MATTERS ARISING

\section{Periarticular bone mineral density at the knee joint}

Recently, dual energy $x$ ray absorptiometry (DXA) was presented by Murphy et al as a new method for assessing periarticular bone mineral density (BMD) at the knee joint. Precision errors for BMD measured at the patella, femur, and tibia were reported for 14 subjects. The paper highlights the emerging importance of measurement of radiological data and attention to regional density characteristics in bone and joint diseases. Subchondral bone mineral density of the proximal tibia has previously been assessed by dua photon absorptiometry (DPA) - the precursor of DXA. Relations between subchondral $\mathrm{BMD}$ of the proximal tibia and age, height, weight, and $\mathrm{BMD}$ of the lumbar spine and femoral neck were examined by Bohr and Schaadt. ${ }^{2}$ Petersen et al presented subchondral BMD values for a large number of healthy subjects and for patients with various orthopaedic conditions. ${ }^{3}$ Bohr and Lund and Petersen et al examined changes in BMD at the proximal tibia after knee arthroplasty. ${ }^{45}$ Petersen et al examined subchondral BMD after meniscectomy, ${ }^{6}$ and Madsen et al reported data for subchondral BMD measured in several subregions of the proximal tibia in healthy subjects and in subjects with osteoarthritis of the knee. ${ }^{7}$ Moreover, Petersen et al studied relations between bone strength and BMD assessed by DPA and DXA in the proximal tibia. ${ }^{8}$ Other related studies could be mentioned. Unfortunately, none of these studies was referred to by Murphy et $a l .{ }^{1}$

O R MADSEN Department of Internal Medicine and Rheumatology E107, Herlev University Hospital, Herlev Ringvej, DK-2730 Herlev, Denmark rintek@dadlnet.dk

1 Murphy E, Bresnihan B, FitzGerald O. Validated measurement of periarticular bone minde ray absorptiometry. Ann Rheum Dis 2001;60:8-13.

2 Bohr HH, Schaadt O. Mineral content of upper tibia assessed by dual photon absorptiometry. Acta Orthop Scand 1987;58:557-9.

3 Petersen MM, Olsen C, Lauritzen JB, Lund B. Bone mineral content assessed by dual photon absorptiometry in the proximal tibia: normative data and measurements in orthopedic conditions. European Journal of Experimental Musculoskeletal Research 1993;2: $121-6$.

4 Bohr HH, Lund B. Bone mineral density of the proximal tibia following uncemented arthroplasty. J Arthroplasty 1987;2:309-12.

5 Petersen MM, Nielsen PT, Lauritzen JB, Lund B. Changes in bone mineral density of the proximal tibia after uncemented total knee arthroplasty. A 3-year follow-up of 25 knees. Acta Orthop Scand 1995;66:513-16.

6 Petersen MM, Olsen C, Lauritzen JB, Lund B, Hede A. Late changes in bone mineral density of the proximal tibia following total or partial medial meniscectomy: a randomized study. J Orthop Res 1996;14:16-21.

7 Madsen OR, Egsmose C, Bliddal H, Sylvest J. Bone mineral distribution of the proximal tibia in gonarthrosis assessed in vivo by photon assorption. Osteoarthritis Cartilage 1994;2: $141-7$.
8 Petersen MM, Jensen NC, Gehrchen PM, Nielsen PK, Nielsen PT. The relation between trabecular bone strength and bone mineral density assessed by dual photon and dual energy x-ray absorptiometry in the proximal tibia. Calcif Tissue Int 1996;59:311-14.

\section{Author's reply}

We appreciate the interest shown in our work ${ }^{1}$ by Dr Marsden. We acknowledge that subchondral bone mineral density has previously been assessed by dual photon absorptiometry. However, we do not feel that this is particularly relevant to our paper. The purpose of our study was to develop and validate a method for measurement of periarticular bone mineral density at the knee joint using the technique now recognised as the gold standard for the assessment of bone mineral density - that is, dual energy $x$ ray absorptiometry (DXA). With the exception of one study, ${ }^{2}$ the studies referred to by Dr Marsden use only dual photon absorptiometry.

As mentioned by Dr Marsden, Petersen et al measured bone mineral density of small regions of interest within the proximal tibia by DXA and used these measurements to investigate the relation between trabecular bone strength and bone mineral density in the proximal tibia. ${ }^{2}$ However, it is not clear from this paper how many measurements were taken for calculation of precision values as the paper concentrates on the use of, rather than the validation of, this technique. Furthermore, the DXA measurements were performed only on postmortem sections of tibial bone obtained at necropsy. Finally, unlike our study, which showed how to measure bone density of periarticular bone, the regions of interest selected by Marsden et al did not include the periarticular surface of tibia, but rather were confined to small areas within the subchondral bone. Thus the areas measured consisted primarily of trabecular bone.

E MURPHY

Education and Research Centre, Department of Rheumatology, St Vincent's Hospital, Elm Park, Dublin 4, Ireland

1 Murphy E, Bresnihan B, FitzGerald O. Validated measurement of periarticular bone mineral density at the knee joint by dual energy $\mathrm{x}$ ray absorptiometry. Ann Rheum Dis 2001; ray absorpt

2 Petersen MM, Jensen NC, Gehrchen PM, Nielsen PT. The relation between trabecular bone strength and bone mineral density assessed by dual photon and dual energy x-ray absorptiometry in the proximal tibia. Calcif Tissue Int 1996;59:311-14

\section{LETTERS TO THE EDITOR}

\section{A mnemonic for SLE diagnostic criteria}

Like many rheumatological diseases, systemic lupus erythematosus (SLE) is difficult to diagnose owing to the constellation of findings required. I offer a mnemonic that contains the 11 categories used by the American College of Rheumatology, ${ }^{1}$ from which four or more must be present to diagnose SLE: A RASH POINts MD.
Arthritis

Renal disease (proteinuria, cellular casts)

ANA (positive antinuclear antibody)

Serositis (pleurisy or pericarditis)

Haematological disorders (haemolytic anaemia or leucopenia or lymphopenia or thrombocytopenia)

Photosensitivity

Oral ulcers

Immunological disorder (positive LE cell, anti-DNA, anti-Sm, false positive serological test for syphilis)

Neurological disorders (seizures or psychosis, in the absence of other causes)

Malar rash

Discoid rash

Because the malar rash is the most easily recalled finding, this mnemonic uses that word and an accompanying message that it "points an MD to a possible diagnosis."

Readers may find this useful in teaching students and residents to remember the many elements of this complex condition.

R LEONARD Graduate student Harvard School of Public Health rleonard@hsph.harvard.edu

1 Tan EM, Cohen AS, Fries JF, Masi AT, McShane DJ, Rothfield NF, et al. The 1982 revised criteria for the classification of systemic upus erythematosus. Arthritis Rheum 1982; 25:1271-7.

\section{Can rheumatologists agree on a diagnosis of inflammatory arthritis in an early synovitis clinic?}

Irreversible joint damage can occur within months rather than years of the onset of rheumatoid arthritis. ${ }^{1}$ It is therefore important that these patients are diagnosed and treated as early as possible. To facilitate the early introduction of effective treatment, a rapid referral system is important. Throughout Europe, a number of centres have developed early synovitis clinics (ESCs) for this purpose. However, the diagnosis of early inflammatory arthritis (IA) is often difficult and confusing for the primary care doctor and experience suggests that the efficiency of ESCs is impaired by inappropriate referrals. ${ }^{2}$ Is this criticism justified? If general practitioners find it difficult to diagnose early IA, what about hospital specialists? In this short study we posed the question "Can rheumatologists agree on a diagnosis of IA in an ESC?"

Patients were recruited from primary care in the greater Belfast area (population ca 400 000). We randomly selected 24 patients who had been referred to an ESC in a Belfast teaching hospital and invited them to attend for outpatient assessment. Informed written consent was obtained from each patient before they took part in the study. Six hospital rheumatologists (two specialist registrars and four consultants) independently assessed 20 patients referred to an ESC by their primary care doctor. Patients were randomly assigned to each rheumatologist, who was asked to judge whether or not the patient currently had any type of IA. Before the study, the assessing rheumatologists had agreed on a definition of IA. Each assessment was conducted in a maximum of 15 minutes, but patients were not informed of their diagnosis until the final consultation, which included an additional 15 minutes to provide time to arrange a management plan for their problems. 
Twenty four patients were invited to participate in the study and 20 consented to take part. Three patients failed to turn up for their outpatient appointment and one patient who did attend declined to take part in the study. There was complete agreement in the assessment of $14 / 20$ patients $(70 \%), 11$ (55\%) of whom were deemed to have IA (including RA, psoriatic arthritis, and reactive arthritis) and three (15\%) who were not. In two cases $(10 \%)$, only one rheumatologist diagnosed IA. In a further two cases $(10 \%)$, only two specialists diagnosed IA and in the final two patients $(10 \%)$, four of the six specialists diagnosed IA. In all cases where there was disagreement, the final assessor shared the majority opinion as to the correct diagnosis. The level of agreement between assessors was calculated using the $\kappa$ statistic, where a value of 1.0 represents total agreement. The overall $\kappa$ value for the six assessors was 0.68 . Interestingly, the registrars had a higher level of agreement $(\kappa 0.9)$ than the consultant rheumatologists ( $\kappa 0.6)$, though the difference was not statistically significant.

These results show that IA can be a difficult diagnosis to make in the setting of an ESC, even among experienced rheumatologists. Nevertheless, the level of agreement in this study compares favourably with that in other specialties such as radiology and ophthalmology. ${ }^{3}$ Given these findings, it is clearly important to keep an open mind about the diagnosis of IA in its early stages, especially where the clinical findings are equivocal. Careful follow up of such patients should be an important part of the work of any ESC.

G GORMLEY K STEELE

D GILLILAND

Department of General Practice, Queen's University of Belfast,

Belfast, $N$ Ireland

M STEVENSON

D O'REILLY

Department of Epidemiology, Queen's University of Belfast

R MCKANE

Department of Rheumatology,

Ulster Hospital,

Belfast, $N$ Ireland

G WRIGHT

A L BELL

C MATTHEWS

G MEENAGH

A J TAGGART

Department of Rheumatology, Musgrave Park Hospital,

Belfast, $N$ Ireland

Correspondence to: Dr Gormley

gerry@teamgormley.freeserve.co.uk

1 Emery P, Green M. The GP's role in optimising early rheumatoid arthritis care. Reports on Rheumatic Diseases. Series Three. Chesterfield Arthritis Research Campaign, 1999, No 18.

2 Gough A, Young A, Bacon P. Objectives and outcome of running an early inflammatory arthritis clinic. Baillieres Clin Rheumatol 1992;6:261-83.

3 Sackett D L, Haynes RB, Guyatt GH. Clinical epidemiology - a basic science for clinical medicine.
London: Little.

\section{Ultrasound guided injection of plantar fasciitis}

Kane et al reported four cases of ultrasound guided injection in recalcitrant idiopathic plantar fasciitis. ${ }^{1}$ We would like to report a different experience using a similar method.
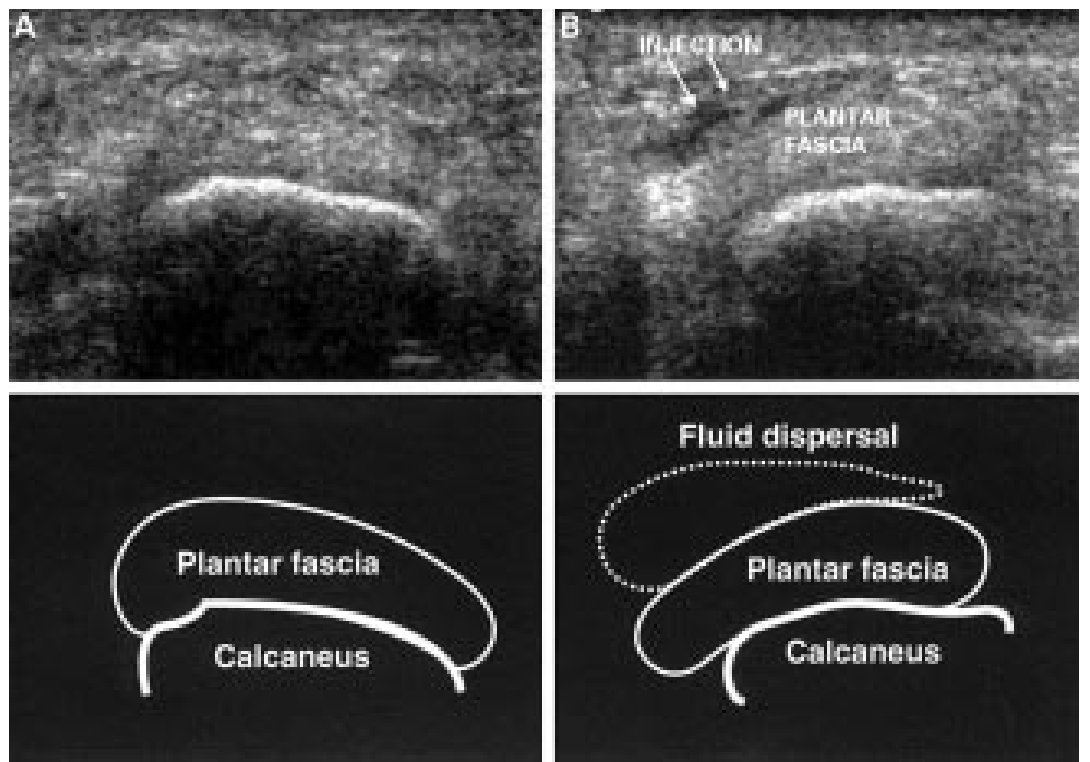

Figure 1 Ultrasound, transverse sections, showing (A) a thickened plantar fascia and (B) fluid dispersal superficial to the plantar fascia.

Two patients with a clinical diagnosis of idiopathic plantar fasciitis, unresponsive to an initial palpation guided injection with $10 \mathrm{mg}$ of triamcinolone acetonide, underwent ultrasound examination of the heel. Increased thickness of the plantar fascia near the calcaneal insertion was noted with both plantar fasciae measuring $7.5 \mathrm{~mm}$ in depth. Under real time ultrasound guidance, using a medial approach, the tip of a 21 gauge needle was positioned in the centre of the plantar fascia. However, on both occasions, considerable resistance was experienced on attempting to inject triamcinolone and lidocaine mixture into the centre of the plantar fascia. Injection was possible only by withdrawing the needle, under ultrasound guidance, to the edge of the plantar fascia where the injected solution was seen to disperse around the edge of the plantar fascia as shown in figs $1 \mathrm{~A}$ and $\mathrm{B}$. Both patients responded well to this treatment, being symptom free on review one month later.

Kane et al described injection directly into the substance of the plantar fascia with dispersal of the injection mixture into the substance of the fascia. Our experience suggests that it is difficult to inject into the substance of the plantar fascia. Rather, one may inject at the edge of the plantarfasciawith perifascial dispersal of steroid. This still appears to result in satisfactory alleviation of symptoms.

$$
\begin{array}{r}
\text { S M WONG } \\
\text { E LI } \\
\text { Department of Medicine } \mathcal{E} \text { Therapeutics, } \\
\text { Prince of Wales Hospital, }
\end{array}
$$
Hong Kong

J F GRIFFITH

Department of Radiology and Organ Imaging, Prince of Wales Hospital Hong Kong

Correspondence to: Dr Wong jsmwong@hkstar.com

1 Kane D, Greaney T, Bresnihan B, Gibney R, FitzGerald O. Ultrasound guided injection of plantar fasciitis. Ann Rheum Dis 1998; 57:383-4.

\section{HLA-DRB1 and DQB1 genes in anticentromere antibody positive patients with SSc and primary biliary cirrhosis}

The frequency of certain HLA class II alleles has been reported to be high in patients with systemic sclerosis (SSc), especially in the clinical subsets defined by SSc related antinuclear antibodies and ethnicity. ${ }^{12}$ In anticentromere antibody (ACA) positive SSc, a high frequency of HLA-DQB ${ }^{\star} 0501$ has

\begin{tabular}{|c|c|c|c|c|}
\hline$D N A$ al & lleles & $\begin{array}{l}\operatorname{SSc\neq }(\%) \\
(n=20)\end{array}$ & $\begin{array}{l}P B C \neq(\%) \\
(n=13)\end{array}$ & $\begin{array}{l}\text { Healthy } \\
\text { control } l^{\prime}(\%) \\
(n=215)\end{array}$ \\
\hline DRB1 & $\begin{array}{l}0101 \\
1502 \\
0401 \\
0403 \\
0405 \\
0406 \\
0802 \\
0803 \\
0901\end{array}$ & $\begin{array}{l}20(8 / 40)^{\star} \\
13(5 / 40) \\
0(0 / 40) \\
8(3 / 40) \\
8(3 / 40) \\
8(3 / 40) \\
3(1 / 40) \\
8(3 / 40) \\
18(7 / 40)\end{array}$ & $\begin{array}{l}8(2 / 26) \\
12(3 / 26) \\
0(0 / 26) \\
0(0 / 26) \\
8(2 / 26) \\
12(3 / 26) \\
0(0 / 26) \\
23(6 / 26) \dagger \\
8(2 / 26)\end{array}$ & $\begin{array}{l}5 \\
11 \\
1 \\
1 \\
11 \\
4 \\
4 \\
7 \\
14\end{array}$ \\
\hline DQB1 & $\begin{array}{l}0301 \\
0302 \\
0303 \\
0401 \\
0402 \\
0501 \\
0502 \\
0601 \\
0602\end{array}$ & $\begin{array}{l}0(0 / 40) \\
20(8 / 40) \\
18(3 / 40) \\
8(2 / 40) \\
0(0 / 40) \\
20(8 / 40) \ddagger \\
5(2 / 40) \\
20(8 / 40) \\
8(3 / 40)\end{array}$ & $\begin{array}{l}4(1 / 26) \\
12(3 / 26) \\
15(4 / 26) \\
8(2 / 26) \\
4(1 / 26) \\
8(2 / 26) \\
0(0 / 26) \\
35(9 / 26) \\
8(2 / 26)\end{array}$ & $\begin{array}{l}13 \\
10 \\
16 \\
11 \\
4 \\
7 \\
2 \\
18 \\
8\end{array}$ \\
\hline
\end{tabular}

Table 1 Gene frequency of selected HLA-DRB1 alleles in anticentromere antibody (ACA) positive patients

${ }^{\star} \mathrm{p}<0.0005, \mathrm{OR}=4.4,+\mathrm{p}<0.01, \mathrm{OR}=3.7, \neq \mathrm{p}<0.005$, $\mathrm{OR}=3.5$.

Difference in alleles was analysed by $\chi^{2}$ test or Fisher's exact test.

When the association with a particular specificity had not been reported previously, $p$ values were corrected $\left(\mathrm{p}_{\text {corr }}\right)$ for the number of alleles tested for each locus (28 in DRB1 and 18 in DQB1). $\ddagger \mathrm{SSc}=$ systemic sclerosis; $\mathrm{PBC}=$ primary biliary cirrhosis.

Seven patients with SSc-PBC overlap were included both in the 20 patients with SSc and the 13 with PBC. 
Table 2 Clinical and laboratory findings of patients with systemic sclerosis (SSc) classified by the presence of anticentromere antibody (ACA) and $H L A-D R B 1^{*} 0803$ allele

\begin{tabular}{|c|c|c|c|c|c|c|c|c|}
\hline \multirow[b]{3}{*}{$D R B 11^{\star} 0803$} & \multicolumn{8}{|l|}{$A C A$} \\
\hline & \multicolumn{3}{|l|}{ Positive $(n=20)$} & \multicolumn{3}{|c|}{ Negative $(n=42)$} & \multicolumn{2}{|l|}{ Total $(n=62)$} \\
\hline & $\begin{array}{l}\text { Positive }(n=3) \\
(15 \%)\end{array}$ & $\begin{array}{l}\text { Negative }(n=17) \\
(85 \%)\end{array}$ & Total $(n=20)$ & $\begin{array}{l}\text { Positive }(n=5) \\
(12 \%)\end{array}$ & $\begin{array}{l}\text { Negative }(n=37) \\
(88 \%)\end{array}$ & Total $(n=42)$ & $\begin{array}{l}\text { Positive }(n=8) \\
(13 \%)\end{array}$ & $\begin{array}{l}\text { Negative }(n=54) \\
(87 \%)\end{array}$ \\
\hline $\mathrm{SS}^{\star}(\%)$ & $2 / 3(67)$ & $9 / 15(60)$ & $11 / 18 \int(61)$ & $5 / 5+(100)$ & $7 / 32+(22)$ & $12 / 37 \oint(32)$ & $7 / 8 \ddagger(88)$ & $16 / 47 \ddagger(34)$ \\
\hline $\mathrm{PBC}^{\star}(\%)$ & $2 / 3(67)$ & $4 / 15(27)$ & $6 / 18+(33)$ & $1 / 5(20)$ & $0 / 37(0)$ & $1 / 42 \dagger(2)$ & $3 / 89(38)$ & $4 / 52 \oint(8)$ \\
\hline Positive for $\mathrm{AMA}^{\star}(\%)$ & $2 / 3(67)$ & $6 / 17(35)$ & $8 / 20 \$(40)$ & $2 / 5(40)$ & $2 / 34(6)$ & $4 / 39 \$(10)$ & $4 / 89(50)$ & $8 / 51 \S(16)$ \\
\hline Positive for SS-A* $(\%)$ & $0 / 3(0)$ & $2 / 17(12)$ & $2 / 20(10)$ & $3 / 5 \subseteq(60)$ & $4 / 35 \$(11)$ & $7 / 40(18)$ & $3 / 8(38)$ & $6 / 52(12)$ \\
\hline
\end{tabular}

${ }^{\star} \mathrm{SS}=$ Sjögren's syndrome; $\mathrm{PBC}=$ primary biliary cirrhosis; $\mathrm{AMA}=$ antimitochondrial antibody; SS-A $=$ anti-Ro/SS-A antibody.

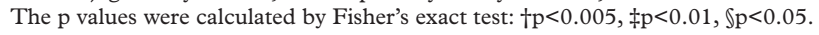

been reported by some investigators. ${ }^{1}$ In addition, we found a high frequency of $\mathrm{DRB} 1{ }^{\star} 0101$ in ACA positive Japanese patients with SSc (J Rheumatol, in press).

ACA is also found in patients with primary biliary cirrhosis $(\mathrm{PBC}),{ }^{3}$ and patients with SSc and ACA commonly overlap PBC or Sjögren's syndrome (SS), or both. ${ }^{4}$ Some studies on HLA class II alleles in Japanese patients with $\mathrm{PBC}$ showed high frequencies of DRB1*0803 and DPB $1{ }^{\star} 0501 .{ }^{5}$ However, we found no reports which analysed HLA class II alleles in patients with PBC with respect to the relation with ACA or SSc.

To clarify the relation of HLA class II alleles with ACA, SSc, and PBC we carried out molecular genetic analyses of HLA-DQB1 and DRB1 alleles ${ }^{6}$ in 86 Japanese patients with SSc or PBC, or both ( $55 \mathrm{SSc}, 24 \mathrm{PBC}$, and $7 \mathrm{SSc}-$ PBC overlap) who had a genetically and racially homogeneous background. These patients were divided into 26 with ACA and 60 without ACA. All patients with SSc were definite SSc fulfilling the American Rheumatism Association's preliminary criteria for SSc, and no patient overlapped with systemic lupus erythematosus, polymyositis/dermatomyositis, or rheumatoid arthritis. For accurate comparison of SSc and PBC, we excluded patients with PBC who had some SSc related features (for example, Raynaud's phenomenon) without satisfying criteria for SSc. The diagnosis of $\mathrm{PBC}$ or SS was established based on the criteria by the Japanese Research Committee. ${ }^{78}$ Healthy controls consisted of 215 unrelated Japanese subjects. ${ }^{59}$

Table 1 summarises the gene frequency in ACA positive patients with SSc or PBC. HLA-DRB ${ }^{\star} 0101$ and $\mathrm{DQB}{ }^{\star} 0501$ were frequently found in SSc, and HLA$\mathrm{DRB} 1{ }^{\star} 0803$ was frequently found in $\mathrm{PBC}$ compared with the healthy controls. These results were consistent with previous reports analysing HLA-DRB1 and DQB1 in patients with SSc or PBC from different institutions. ${ }^{15}$

In PBC, no difference in phenotype frequency (the number of patients positive for an allele) of DRB $1{ }^{\star} 0803$ was found between ACA positive patients and ACA negative ones $(6 / 13(46 \%)$ v 5/18 (28\%)). Patients with $\mathrm{PBC}$ who were ACA positive frequently overlapped SSc compared with ACA negative patients $(6 / 13(46 \%) \vee 1 / 18(6 \%), \mathrm{p}<0.05)$. On the other hand, DRB $1^{\star} 0803$ in PBC showed no association with overlapping SSc; phenotype frequency of $\mathrm{DRB} 1{ }^{\star} 0803$ was $43 \%(3 / 7)$ in SSc-PBC overlap and 33\% $(8 / 24)$ in PBC without SSc related features.

Table 2 shows clinical analyses in patients with SSc classified by the presence of ACA and DRB $1^{\star} 0803$. Phenotype frequency of DRB $1{ }^{\star} 0803$ was not different between ACA positive SSc and ACA negative SSc. ACA positive SSc frequently overlapped SS and PBC compared with ACA negative SSc. In ACA negative SSc, DRB $1{ }^{\star} 0803$ positive patients frequently overlapped SS compared with DRB $1^{\star} 0803$ negative ones, and one of the five patients with DRB $1{ }^{\star} 0803$ overlapped PBC. DRB ${ }^{\star} 0803$ may be a candidate allele to determine the susceptibility to SS and PBC in patients with SSc with no relation to the presence of ACA, and the existence of common candidate alleles in PBC and SS may explain the high frequency of overlap of both the diseases. ${ }^{10}$ There was no significant difference in skin sclerosis or organ involvement in patients with SSc classified by the presence of DRB1*0803 (data not shown).

Our report describes the variation of HLA class II alleles among ACA positive patients according to their clinical features; high frequency of HLA-DRB $1^{\star} 0101 /$ $\mathrm{DQB} 1{ }^{\star} 0501$ and $\mathrm{DRB}{ }^{\star} 0803$ are restrictively found in SSc and PBC, respectively. Although DRB1*0803 is not related to the production of ACA, this allele may be related to the susceptibility not only to PBC but also to SS in patients with SSc.

We thank Dr Takehiko Abe and Dr Akira Kojima, The First Department of Internal Medicine, for their help in collecting blood samples from patients with PBC.

This study was partly supported by grants from Kanzawa Medical Research Foundation (1999) and a Scleroderma Grant for Intractable Disease from the Japanese Ministry of Health and Welfare (1999).

S AKIMOTO

$M A B E$

O ISHIKAWA

Department of Dermatology, Gunma University School of Medicine,

fapan
H TAKAGI

M MORI

The First Department of Internal Medicine, Gunma University School of Medicine,

fapan

Correspondence to: Dr S Akimoto, Department of Dermatology, Gunma University School of Medicine, 3-39-22 Showa-machi, Maebashi, Gunma 371-8511, Japan

1 Kuwana M, Okano Y, Kaburaki J, Inoko $\mathrm{H}$. HLA class II genes associated with anticentromere antibody in Japanese patients with systemic sclerosis (scleroderma). Ann Rheum Dis 1995;54:983-7.

2 Kuwana M, Kaburaki J, Arnett FC, Howard $\mathrm{RF}$, Medsger TA Jr, Wright TM. Influence of ethnic background on clinical and serologic features in patients with systemic sclerosis and anti-DNA topoisomerase I antibody. Arthritis Rheum 1999;42:465-74.

3 Makinen D, Fritzler M, Davis P, Sherlock S. Anticentromere antibody in primary biliary cirrhosis. Arthritis Rheum 1983;26:914-17.

4 Akimoto S, Ishikawa O, Muro Y, Takagi H, Tamura T, Miyachi Y. Clinical and immunological characterization of patients with systemic sclerosis overlapping primary biliary cirrhosis: a comparison with patients with systemic sclerosis alone. J Dermatol 1999;26: $18-22$.

5 Onishi S, Sakamaki T, Maeda T, Iwamura S, Tomita A, Saibara T, et al. DNA typing of HLA class II genes; DRB $1^{\star} 0803$ increases the susceptibility of Japanese to primary biliary cirrhosis. J Hepatol 1994;21:1053-60.

6 Kaneshige T, Hashimoto M, Matsumoto Y, Kinoshita T, Hirasawa T, Uchida K, et al. Serologic and nucleotide sequencing analyses of a novel DR52-associated DRB1 allele with the DR'NJ25' specificity, designated DRB1*1307. Hum Immunol 1994;41:151-9.

7 Sasaki H, Inoue K, Higuchi K, Yasuyama T, Koyata $\mathrm{H}$, Kuroki $\mathrm{T}$, et al. Primary biliary cirrhosis in Japan: national survey by the subcomittee on autoimmune hepatitis. Gastroenterologica Japonica 1985;20:476-85.

8 Homma M, Tojo T, Akizuki M, Yamagata $H$. Criteria for Sjögren's syndrome in Japan. Scand J Rheumatol Suppl 1986;61:26-7.

9 Hashimoto $M$, Kinoshita $M$, Yamasaki $M$, Tanaka H, Imanishi $T$, Ihara $\mathrm{H}$, et al. Gene frequencies and haplotypic associations within the HLA region in 916 unrelated Japanese individuals. Tissue Antigens 1994;44:166-73.

10 Uddenfeldt P, Danielsson Å, Forssell Å, Holm M, Östberg Y. Features of Sjögren's syndrome in patients with primary biliary cirrhosis. J Intern Med 1991;230:443-8. 